\title{
Towards a New Paradigm of Vocational Learning
}

\author{
Paul Hager \\ University of Technology, Sydney
}

This chapter begins with a consideration of the origins of vocational learning, showing that for most of its history it was an on-the-job activity. With the rise of compulsory formal education systems late in the nineteenth century, vocational learning was gradually absorbed into formal arrangements, in the process being reconceptualised around influential assumptions that have shaped formal education systems and wider public understandings of learning. It is argued that the result has been that recent growing interest in on-the-job learning has been warped by unconscious adherence to inappropriate formal education assumptions. The deficiencies of the recent competencies agenda and its implementation is traced to these kinds of assumptions. Hence, this chapter concludes, we need a new account of vocational learning. Some recommended features of such an account are sketched briefly.

\section{The historical genealogy of vocational learning - on-the-job learning}

Of necessity, vocational learning was originally an on-the-job phenomenon - as early humans struggled for survival as hunters and gatherers, the younger family and clan members were doubtless inducted into what were literally 'life skills' by their elders. It is likely that some were more adept at the mentoring of novices than others, so it was natural for them to assume roles as mentors/tutors. If so, this was an early example of work segmentation and specialisation. With the rise of agricultural practices, people could live successfully in one place, hence the growth of villages and towns. Thus, viable farming practices accelerated the segmentation of the labour force into diverse occupations. Thus the institution of apprenticeship was born. The coming of the industrial revolution further enhanced these trends as towns grew into cities, and villages into towns. Throughout all of these developments, vocational learning remained an on-the-job phenomenon. Certainly, with the rise of apprenticeship, such learning was made more formal in various ways, but it was still essentially something that occurred on-the-job. It was well into the nineteenth century before the first moves occurred to shift vocational learning decisively towards off-the-job delivery. This was ultimately to lead to the rise of formal vocational education and training (VET). A main theme in this rise of VET was the centrality of morally uplifting knowledge in off-the-job vocational learning. In this there was no conception that workers were learning skills that would directly enable them to do their job better. Rather the aim was for workers to become better persons by acquiring the scientific disciplinary knowledge connected to their occupation.

These developments will be illustrated by considering the case of Australia, which consisted of a series of British colonies till the start of the twentieth century. For this reason, it seems that the developments in Australia closely followed a similar sequence in Britain. This account of the rise of formal vocational learning in Australia draws heavily on the work of Murray-Smith $(1965,1966)$, who was the acknowledged doyen of historians of Australian technical education up till the 1970s. (The term 'technical 
education' was used in Australia until the 1970s when it was replaced by Technical and Further Education (TAFE). By the 1990s the wider term 'VET' gained currency).

According to Murray-Smith, up till 1965 Australian technical education went through five distinct periods. These mirrored similar developments in Britain. The first period, from the founding of the colony of NSW in 1788 to about 1850, is marked by ..... intellectual, middle class ideas on the social usefulness of instructing the intelligent artisan in the scientific principles underlying his trade ....

(Murray-Smith 1965, p. 171)

The first half of the nineteenth century saw the establishment of mechanics' institutes in many parts of Australia. This movement was accompanied by prominent slogans imported from Britain, such as "self-improvement for the labouring classes”. The point that needs to emphasised is that this movement, which marked the beginnings of formal VET provision, did not see itself as providing workers with knowledge necessary to carry out their occupation.

Education was a moral and often a charitable question, but hardly one of practical utility. Even the radicals who, in the home country, were challenging conservative forces and espousing the cause of instruction for the common people did so for 'higher' reasons - because it accorded with their views of the proper and rational conduct of human affairs and the social sobriety that the spread of knowledge would bring.

(Murray-Smith 1966, p. 5)

Organisations of many kinds sprang up, dedicated to the diffusion of useful knowledge to the working class. Summarising this first period, Murray-Smith concludes:

Perhaps the most important single lesson that history teaches us about the development of technical education in Australia is that it has sprung less from a direct and uncomplicated response to a real lack of skills in the community than from a complex of strongly-held philosophical, moral and social ideas. The precise definition of these ideas changes from time to time but, at least until the twentieth century, they are alike in the assumption they share that the benefits of imparting 'useful' knowledge far transcend the merely material ends to be gained.

(Murray-Smith 1966, p. 6)

Though, according to Murray-Smith, the mechanics' institutes and related organisations flourished to a greater degree in Australia than in Britain, "their educational ambitions never succeeded" (1966, p. 8). This was because they presented lecture series offered by volunteers teaching what interested them personally rather than a program based on what the students might want or need. The result was that classes seldom lasted for longer than a few weeks at a time. In most cases, it seems, the pedagogy was woeful.

In Murray-Smith's second period (1850-1890), haphazard developments “coalesce into a well-defined stream” (1965, p. 171). One by one Australian state governments (still all 
separate British colonies) set up "semi-autonomous government instrumentalities" (Murray-Smith 1965, p. 178) to direct the mechanics' institutes, schools of mines, etc. (By 1890 there were ten schools of mines in Victoria alone - Murray-Smith 1965, p. 179). Importantly, over this period of initial government involvement,

.... the moral content of the 'diffusion of knowledge' movement leached away but its social and physical implications remained.

(Murray-Smith 1966, p. 9)

The focus was gradually shifting to a conception that skilled workers, at least, were entitled, as citizens, to receive some form of systematic education. This was the era when compulsory primary education was being instituted. So the mechanics' institutes, schools of mines, etc. became a sort of "poor persons' university" at a time when there was minimal state provision of secondary education. The institution of compulsory primary education

.... was now producing a generation of ambitious young men and women excluded from the middle-class grammar schools but still thirsting for educational and social advancement.

(Murray-Smith 1966, p. 13. See also 1965, p. 177ff)

In this second period, the "old slogan of 'self-improvement' is not so much being dropped, but is metamorphosing” (Murray-Smith 1966, p. 13). Morality is still a consideration, but

..... the framework in which it applies is now much harder-headed. Advancement, mobility, a sense of national purpose are becoming much more a part of the ethos of the community.

(Murray-Smith 1966, p. 13)

In 1862, John Wooley, foundation professor of the University of Sydney, stated: "The cry of our fathers was for 'the general diffusion of knowledge'; ours is its 'utilisation'” (quoted by Murray-Smith 1966, p. 10). Education for economic advancement was an idea beginning to take hold.

But the point I really want to emphasise here is that in all of these developments the focus is single-mindedly on knowledge that represents a background to work, rather than on learning how to perform work itself. For that, on-the-job learning is viewed as essential:

'Technological instruction', Marcus Clarke wrote as late as 1871, 'does not aim at the mere furtherance of manipulative skill'. It was the theory underlying trades and crafts in which the institutes hoped the working man (sic) would be interested, not the practical applications. It was held that skills themselves were a matter for the workshop, and indeed no institute would have had the space, the money or the equipment to teach trades even if the idea of so doing had been intellectually acceptable. 
(Murray-Smith 1966, p. 8)

So strong was this idea of the social benefits of education for trades and crafts people that by the end of Murray-Smith's second period

.... the whole question has what the Melbourne Age called a 'firm hold ..... on the public mind'; it becomes, in fact, perhaps the most widely debated question of the day.

(Murray-Smith 1965, p. 171)

As Murray-Smith suggests, it is a firm indication of the almost fetishistic value that came to be placed on technical education, that by the late 1880s in many Victorian country towns it was as much the right thing to have a school of mines as it was to have a town hall or post office with a tower on it. The placation of electors with money to start a technical school of some kind even became an established form of political bribery.

(Murray-Smith 1966, p. 13)

However, the poor organisation persisted. Aims were ill-defined and lack of resources meant that often courses were adapted to popular non-vocational requirements, thus drawing criticism that the institutes were failing to meet their main purposes. For instance, the Age in 1887 complained vociferously that

.... the parliamentary vote to schools of mines, designed to produce practical miners, was being 'expended', in a large measure, in teaching young ladies the accomplishment of landscape and animal drawing.

(Murray-Smith 1965, p. 179)

In these circumstances, it is not surprising that the states intervened further to provide more direction. This marks Murray-Smith's third period (1890-1914) during which governments sought to impose more order and purpose on VET, and to position it in relation to primary education on the one hand and secondary education and universities on the other. However, at the same time, a series of external developments meant that the public interest in VET started to wane, as did the urgency for governments to place it on a better footing. These developments included:

- the severe depression of the 1890 s which greatly cut funding

- the rapid decline of mining in Australia

- the retreat of Australian industry behind tariff barriers and a reduction of interstate economic rivalries, both brought about by Federation.

So the result was that any progress in VET in this period was very slow, while teachers remained "untrained, overworked and ill-paid" (Murray-Smith 1965, p. 183). As well, VET schools were badly located to meet pressing needs, and course offerings were poorly-planned and conceptualised. Overall, as Murray-Smith (1965, p. 182) pointed out, it is a plausible view that

.... the assumption of control of technical education by the state departments about the year 1890 was a serious setback to its development. 
Nevertheless, "by 1914, technical education had clarified its function” (Murray-Smith 1966, p. 22) and assumed its shape for the next half century. In the process, though, as Murray-Smith observes:

..... the academic bias of the high schools, and the influence of the state examination systems, tended to impart to technical education a 'second-class' prejudice that we still linger under today.

(Murray-Smith 1965, p. 186).

The result of arriving finally within the educational mainstream, but with 'second-class' status, was that VET from now on was frequently dubbed the 'Cinderella' of the educational system. It seems that things were little different in Britain. As Connell (1980, p. 50) observed:

Technical education in England was the Cinderella of education. It was unplanned, inadequately financed and looked on without enthusiasm by employers, employees, and educators. A government report of 1918 estimated that in 1914 only seven per cent of the male population was receiving any kind of technical instruction.

Out of this later development, the main point that I wish to stress is that from now on, the assumption that had characterised vocational learning throughout its previous history, that it is essentially an on-the-job activity, starts to be revised. Rather than providing background understanding of principles that underpin work, thereby offering further education, the role of VET gradually shifts to one of preparing people for work.

Moreover, this role is increasingly perceived in terms of assumptions about learning that characterise the formal education system as a whole. I turn to this in the next section.

The incorporation of vocational learning into the formal education system leads to Murray-Smith's fourth period, which spans the interwar years. This period is "one in which achievements are modest and the pace of development slow” (1965, p. 171). In fact, this period is the culmination of what Murray-Smith dubs "a long sleep of half-acentury” for VET (1966, p. 1). His final period is one in which interest in vocational learning is reawakened - leading eventually to the major reforms of the 1990s. We turn to these later in the chapter.

\section{Vocational learning incorporated into the formal education system}

The main claim in this section is that as vocational education and learning became incorporated more and more into the formal education system, albeit as the poor cousin, so they came to adopt typical formal education assumptions and a supply side focus. These formal education assumptions become so strong that their unsuitability for vocational learning is now but dimly recognised. These assumptions centre on a common story about learning - the 'common sense' account - that goes something like this. The best learning resides in individual minds not bodies; it centres on propositions (true, false; 
more certain, less certain); such learning is transparent to the mind that has acquired it; so the acquisition of the best learning alters minds not bodies. Subsidiary threads of the story include: the best learning can be expressed verbally and written down in books, etc.; the process and product of learning can be sharply distinguished; and, though residing in minds and books, the best learning can be applied, via bodies, to alter the external world.

There are a number of basic presuppositions about learning that underpin this story. The main one is:

- There is one best kind of learning, the furnishing of minds with true propositions.

Though it is recognised that learning comes in distinct kinds, according to this assumption, the relative worth of all types of learning is to be judged against the best, viz acquisition of propositions by minds. This major presupposition centrally underpins the above story. Closely related to it are two other presuppositions as follows:

- Learning centres on the stable and enduring. Since true propositions are in some sense unchanging and enduring, the best kind of learning remains relatively stable over time.

- Learning is replicable. If the best kind of learning is something that is stable and enduring, then the learning of different learners can be literally the same or identical. ${ }^{\mathrm{i}}$

Taken together these three presuppositions represent a focus on 'adding more substance' to the mind. Viewing learning as the accumulation of mental products is what Bereiter (2002) dubs the 'folk theory' of learning. One effect of this emphasis on the products of learning is that performance of human activities that have a substantial theoretical base is thought of as involving two distinct components. Firstly, the mind is thought to acquire the requisite quota of theoretical items. Secondly, performance is thought to involve the application of these theoretical items. It is assumed that lack of these theoretical items will entail unsatisfactory practice. But, particularly as the twentieth century unfolded, the requisite theoretical base of most of the occupations catered for by VET was perceived to have expanded greatly. Hence the theoretical content of typical VET courses grew apace.

This account of what is needed to acquire occupational proficiency, shaped by the learning as product assumption, has come to dominate VET systems in the following ways:

- Selection of Students: admission criteria that are based overwhelmingly on individual performance on written tests of propositional knowledge, and which, in effect, test the individual's mental capacity.

- Curriculum: course content that is overwhelmingly propositional knowledge logically ordered via disciplines and subjects. Any non-propositional learning, such as workshop practice or laboratory skills, is driven by the propositional, i.e. it involves application of theory covered previously in the classroom. If not, this is regarded as a flaw in curriculum structure. 
- Teaching Methods: the major focus is on presentation of verbal and written propositions for individual student acquisition and understanding. Hence the dominant use of lectures, tutorials and textbooks.

- Assessment/Progression Methods: learning is demonstrated by individuals reproducing verbal or written propositions in appropriate combinations in response to set questions in examinations, preferably unseen, and written assignments. There is a focus on universal, context free knowledge, with numbers and grading to quantify the amount of learning demonstrated.

Taken together, these academic processes support the 'front-end model' of occupational preparation. The term 'front-end model' refers to any instance of vocational preparation that is based on a period of formal education and/or training that needs to be completed by entrants to the occupation before they can be regarded as qualified workers (Beckett \& Hager 2002, p. 100ff., Hager 2004a). The formal education and/or training usually takes place in classrooms remote from the workplace. This model is called 'front-end' because it implies that all of the learning that is needed for a lifetime of practice has been completed. ${ }^{\text {ii }}$ The front-end model has become dominant in vocational preparation of all kinds. This is most obvious in professional and sub-professional occupations where a period of some years study in a formal educational institution, such as a university, is typically a prerequisite for entry into the occupation. However, the front-end model has been influential also in the area of the trades and other skilled occupations where there has been more recognition of the importance of on-the-job learning for novices. In these and other occupations a mandatory period of formal education or training has become increasingly common. .ii $^{\text {ii }}$

So VET systems have been shaped markedly by the assumptions of the learning as product view that has been highly influential in shaping formal education systems.

\section{The recent revival of on-the-job learning - the pendulum swings back}

There are various reasons for the recent revival of interest in on-the-job learning. The two major ones will be considered here. Firstly, the 'learning as a product' view is under increasing critical pressure for a variety of reasons both theoretical and practical. Five current problems/issues in educational theory and practice that are connected with questioning of the 'learning as a product' view are discussed briefly below.

(i) Failures of theory/practice accounts of performance

If, as the common story of learning suggests, the most valuable learning resides in minds that are essentially passive spectators, then this will be the basis for understanding human performances that are significantly cognitive. Hence the view that such performances are practices that involve the application of previously acquired theory. Long ago Ryle pointed out the futility of this view which effectively seeks to reduce practice to theory. Though still the common sense view of performance, the theory/practice account is increasingly seen to be implausible. These increasing doubts have been fuelled by research on expertise and the rise of the knowledge society, both of which emphasise the creation of valuable knowledge during the performance of work. Better concepts that 
involve more relevant assumptions might yet produce a conceptual understanding of practice. (See Beckett \& Hager, 2002, pp. 130-32).

(ii) Failures of the front-end model of vocational preparation These include:

- the increasing realisation that front-end courses in themselves are insufficient to prepare novices for a lifetime of practice.

- the growing rejection of the technical-rationality assumption that underpins many front-end vocational preparation courses.

- growing doubts about the capacity of the front-end model to prepare practitioners for accelerating change. (For more discussion see Beckett \& Hager, 2002, pp. 101-5).

(iii) Research in higher education learning

Resting on concepts such as surface vs. deep learning, a range of research has found that much learning is higher education is far from optimal (e.g. see Bowden \& Marton, 1998, Prosser \& Trigwell, 1999). It is often found that “.... despite students’ having successfully negotiated the assessment system, little understanding of fundamental concepts has been gained” (Bowden \& Marton 1998, p. 61). Perhaps the conclusion from this is that even learning a traditional discipline is a gradual process of growing understanding, rather than discrete bit-by-bit mastery. This would suggest that gaining high level proficiency in a discipline more resembles the 'gradual clearing of a fog in a landscape' than atom-by-atom acquisition of content.

(iv) New directions in psychology

There is a clear move away from learning as a mind being stored with contents (e.g. Bruner, 1996, Bereiter, 2002,). As Bereiter puts it”

... everyday cognition makes more sense if we abandon the idea of a mind operating on stored mental content and replace it with the idea of a mind continually and automatically responding to the world and making sense of whatever befalls it. I call this the 'connectionist view of mind'...

(Bereiter, 2002, pp. 196-7).

\section{(v) Learning transfer research}

Learning transfer research has led to recent proposals to reconceptualise transfer and, by implication, learning (e.g. Bransford \& Schwartz, 1999, Schoenfeld, 1999). Researchers see the institution of formal education being underpinned by the basic assumption that transfer is a ubiquitous phenomenon. However despite increasing power of experimental techniques, transfer "seems to vanish when experimenters try to pin it down" (Schoenfeld, 1999, p. 7). As Bransford \& Schwartz (1999) point out, transfer is indeed rare if it is restricted to 'replicative' transfer, which involves both the stability and replicability assumptions that were noted above. However, they propose that we broaden the notion of 'transfer' by including an emphasis on 'preparation for future learning', the ability to learn in new environments. So the point of transfer is not replication of a product. 
Each of these problems/issues involves rejection in one way or another of the learning as a product view and directs attention to on-the-job learning as an interesting phenomenon in its own right.

This brings us to the second main reason for the recent revival of interest in on-the-job learning, the concern to better align learning in formal courses with the knowledge and skills required in workplaces. This has been accompanied by interest in such matters as the transition from novice to skilled practitioner, a process in which some form of on-thejob learning appears to be essential. One main manifestation of the attempt to bridge onand off-the job learning has been the so-called competencies agenda. In many countries, occupational competencies have been developed as part of policies that sought to revitalise vocational education and training, usually with the stated overriding aim of becoming more competitive in the globalised economy. These developments have drawn strong criticism from many educators, and, in some cases, have resulted in dubious education and training offerings. Here, I will argue that much of the confusion about competence can be traced to both its proponents and opponents variously sharing certain questionable assumptions about learning that revolve around viewing it as a product. The result is ambiguity and equivocation as both camps run together items that are logically and conceptually distinct. In particular, to advance these matters we need to make consistently a tripartite distinction between:

- Performance and its outcomes.

- The underpinning constituents of competence (capabilities, abilities, skills).

- The education, training or development of people to be competent performers.

(Hager 2004b)

Firstly, for descriptions of performance and its outcomes, precision is possible and attainable. (The term 'performance' relates to human activity of some kind). Secondly, however, when it comes to the underpinning constituents of competence (capabilities, abilities, skills), no such precision is attainable. These constituents of competence are attributes or properties of people. We infer on the basis of performance various propositions about a person's capabilities, abilities, and skills. But this remains territory where contestation is inevitable. Thirdly, when it comes to the education, training or development of people to be competent performers, we enter a completely new dimension, since the development of competence and competence itself are logically different categories. As well, education, training or development outcomes are different from performance outcomes.

This chapter has argued that basic principles of on-the-job learning clash with formal education assumptions. Competencies provide an illustration of this. Various errors abound in discussions about competence which stem from viewing it as a product. The first of these errors equates performance and outcomes with skills and capabilities. The 'folk theory' of learning encourages this error. If learning is thought of as coming in discrete, 'bite-sized' chunks, then acquiring a new skill is like adding an extra tool to one's repertoire. Also if learning is transparent and relatively stable, then the acquisition of a new skill should be observable in some sense. Given these assumptions, the 
difference between the performance of a psychomotor skill and the possession of such a skill shrinks to almost nothing. Likewise, if skills are acquired as discrete units, then performance becomes a sum of the relevant skills.

When performance and outcomes are equated with skills and capabilities, it follows that if we can give precise specifications of performance and outcomes, then we can do the same for skills and capabilities. But, skills and capabilities are at best an inference from performance and outcomes, with the latter, but not the former, being 'amenable to being tied down to clear-cut specifications or rules' (Hager 2004b).

This brings us to a second widespread error about competence. As Lum (1999, p. 410) puts it, it is the assumption that "human capabilities can be unequivocally described and accurately communicated by means of language”. This is an unfounded hope. Whereas we commonly make inferences about a person's capabilities, abilities, and skills on the basis of performance, such attributions always involve assumptions about the nature of these capacities. The nature of the capabilities, abilities, and skills involved in performances of various kinds are typically contested, as also is the best way to develop such capabilities, abilities, and skills.

Once again, viewing learning as product is the problem. It discounts learning that is nontransparent as inferior. Hence the natural slide to think that the person's competence (capabilities, abilities, or skills) can be directly specified. Since the learning as product view also thinks in terms of piecemeal acquisition of discrete, stable capabilities, abilities, or skills, the concept of two people acquiring the same replicable repertoire of competencies makes sense. ${ }^{\text {iv }}$

Overall, both proponents and opponents of competence, influenced the common sense view of learning, have made grave errors in conceptualising and implementing competence approaches.

\section{The need for a new account of vocational learning}

The previous sections have argued that attempts to bridge on- and off-the job learning are doomed to failure as long as our understanding of vocational learning is skewed by inappropriate assumptions taken over uncritically from formal learning situations. The competencies discussion illustrated this. So we need a new understanding of vocational learning.

Three key ideas necessary for developing such an understanding will be discussed briefly in this section. Firstly, learning needs to be viewed as an ongoing process. This requires more understanding than hitherto that learning from the practice of an occupation is at least as important, if not more so, as the formal learning that precedes full entry into the occupation. Learning being an ongoing process is quite consistent with performance descriptors being devised for various stages or levels of the ongoing learning process and learners being assessed against those performance descriptors for various purposes. 
Dewey was a pioneer of the conception of learning as a process (or, more accurately, as a dialectical interplay of process and product). The sharp distinction between process and product of learning is plausible whenever learning is separated from action. However, when learning is closely linked with action, the two are not sharply distinguished at all. The process facilitates the product which at the same time enhances further processes and so on. (While bearing in mind the dialectical interplay of process and product, in the following I will refer to 'learning as process' for the sake of simplicity). Dewey's ideas were widely noted and discussed. However they cannot be said to have transformed educational thought, let alone practice, as the ongoing persistence of the learning as product view shows. However, recent developments in educational thought have brought the notion of learning as a process into new prominence. Bereiter's connectionist view of the mind as an entity that continually and automatically responds to the world, making sense of whatever befalls it, is an example. Likewise, the Bransford \& Schwartz concept of 'preparation for future learning' centres on learning as a process rather than as a product. More generally, influential contemporary approaches to understanding learning centre on viewing it as a process, e.g. Lave and Wenger (1991), Engestrom (2001).

Secondly, a new understanding of vocational learning needs to recognise that, in an important sense, learning is wider than the individual learner. Learning reshapes the learner and the environment, i.e. its sets up a network of relations that extends beyond the individual learner. So while some learning can be seen as residing in individuals, other important learning occurs at the level of teams and organisations. This is why 'transfer' is actually most often new learning as the learner/environment package is seldom the same or very similar. As well the significance of the social nature of learning needs consideration.

Thirdly, a new understanding of vocational learning needs to think much more widely than mere skill or propositional learning. What we have is an integration of cognitive, conative and affective capacities as well as other abilities and learned capacities such as bodily know-how, skills of all kinds, and so on. Not all of these components are expressed verbally or written down. All of these are components conceivably involved in making and acting upon judgements. These judgements reflect a capacity for successful acting in and on the world (see Beckett \& Hager 2002, p. 150).

A system of vocational learning that centred on these three features would differ significantly from current arrangements.

\section{Conclusion}

This chapter began by showing that for most of its history, vocational learning was an onthe-job activity. Public understandings of the nature of learning, shaped by compulsory participation in formal education systems, are less than helpful for understanding on-thejob learning. For that, it has been argued, we are in urgent need of a new account of vocational learning, one that takes account of the value of on-the-job learning. Some likely features of such an account have been outlined briefly. 


\section{References}

Beckett, D. \& Hager, P. (2002) Life, Work and Learning: Practice in Postmodernity. Routledge International Studies in the Philosophy of Education 14. London and New York: Routledge.

Bereiter, C. (2002) Education and Mind in the Knowledge Age. Mahwah, N.J./London: Lawrence Erlbaum Associates.

Bowden, J. \& Marton, F. (1998) The University of Learning. London: Kogan Page.

Bransford J.D. \& Schwartz, D.L. (1999) Rethinking Transfer: A Simple Proposal With Multiple Implications, Review of Research in Education, 24, pp. 61-100.

Bruner J. (1996) The Culture of Education. Cambridge, Mass./London: Harvard University Press.

Connell W.F. (1980) A History of Education in the Twentieth Century World. Culture and Curriculum Series. Canberra: Curriculum Development Centre.

Engestrom, Y. (2001). Expansive Learning at Work: Towards an Activity-Theoretical Reconceptualisation, Journal of Education and Work, Vol. 14, No. 1, pp. 133-156.

Hager P. (2004a) Front-Loading, Workplace Learning and Skill Development, Educational Philosophy and Theory, Vol. 36, No. 5, pp. 523-534.

Hager P. (2004b) The Competence Affair, or Why Vocational Education and Training Urgently Needs a New Understanding of Learning, Journal of Vocational Education \& Training, Vol. 56, No. 3, pp. 409-433.

Hager P. (2005) Philosophical Accounts of Learning, Educational Philosophy and Theory, Vol. 37, No. 5, pp. 649-66.

Lave J., \& Wenger E. (1991). Situated Learning. Cambridge: Cambridge University Press.

Lum G. (1999) Where's the Competence in Competence-based Education and Training?, Journal of Philosophy of Education, Vol. 33, No. 3, pp. 403-18.

Murray-Smith S. (1965) Technical Education in Australia: A Historical Sketch, in E.L. Wheelwright (ed.) Higher Education in Australia. Melbourne: F.W. Cheshire.

Murray-Smith S. (1966) Technical Education: The Lines of Development, in C. Sanders (ed.) Technical Education for Development. Nedlands, Western Australia: University of Western Australia Press. 
Prosser M. \& Trigwell K. (1999) Understanding Learning and Teaching: The Experience in Higher Education. Buckingham/Philadelphia: Society for Research into Higher Education \& Open University Press.

Schoenfeld A.H. (1999) Looking Toward the $21^{\text {st }}$ Century: Challenges of Educational Theory and Practice, Educational Researcher, Vol. 28, No. 7, pp. 4-14.

${ }^{\mathrm{i}}$ For a fuller account and critique of these and other presuppositions not specifically considered here see Hager 2005.

ii A kind of front-end model can also be seen as being virtually the only one shaping primary and secondary schooling. In this case the vocation is 'adult member of society' and some minimal period of schooling is deemed both essential and sufficient for preparation of all youth for this role.

iii In Australia, for example, a system of one year traineeships, that include a formal education component, has been instituted over the last decade for a wide range of occupations not covered by apprenticeships. These occupations previously lacked a formal training component.

${ }^{\text {iv }}$ For more examples of pervasive errors about competence see Hager 2004b. 